\title{
Case Report \\ Dual Ectopic Thyroid with Normally Located Thyroid: A Case Report
}

\section{Bipul Kumar Choudhury, ${ }^{1}$ Uma Kaimal Saikia, ${ }^{1}$ Dipti Sarma, ${ }^{1}$ Mihir Saikia, ${ }^{1}$ Sarojini Dutta Choudhury, ${ }^{1}$ Santanu Barua, ${ }^{2}$ and Swapna Dewri ${ }^{3}$}

\author{
${ }^{1}$ Department of Endocrinology, Gauhati Medical College, Guwahati, Assam 781032, India \\ ${ }^{2}$ Nucleomed Imaging and Diagnostics, Guwahati, Assam 781005, India \\ ${ }^{3}$ Department of Pathology, Gauhati Medical College, Guwahati, Assam 781032, India
}

Correspondence should be addressed to Uma Kaimal Saikia, umakaimals@yahoo.co.in

Received 14 November 2010; Accepted 20 April 2011

Academic Editor: Marian Ludgate

Copyright (C) 2011 Bipul Kumar Choudhury et al. This is an open access article distributed under the Creative Commons Attribution License, which permits unrestricted use, distribution, and reproduction in any medium, provided the original work is properly cited.

\begin{abstract}
Dual ectopic thyroid is a rare presentation of thyroid ectopia. Only a few cases have been reported in the world literature. Dual ectopic thyroid in the presence of a normally located thyroid is even rarer. We report a case of dual ectopic thyroid in the lingual and submandibular areas in a seventeen-year-old female with hypoplastic thyroid gland in its normal location. The patient presented with a midline swelling at the base of tongue with dysphagia. Thyroid function test revealed primary hypothyroidism. Ultrasonography of the neck showed hypoplastic thyroid in its normal location. A thyroid scan with Technetium-99 m pertechnate showed two intensely hyperfunctioning foci of ectopic thyroid tissue at a higher level in the midline consistent with dual ectopic thyroid, one at the base of tongue and the other in submental region. No uptake was seen in the normal bed.
\end{abstract}

\section{Introduction}

Ectopic thyroid is a developmental defect of thyroid gland that leads to presence of thyroid tissue at sites other than its normal cervical location. It is frequently found along the course of the thyroglossal duct but can also be found at remote distant sites. Lingual thyroid is the most common presentation of ectopic thyroid. It is very rare to have two ectopic foci of thyroid tissue, and only a very few cases of dual ectopia have been reported in the world literature. In $70 \%$ of cases of ectopic thyroid, the normal thyroid gland is absent. It is extremely rare to have dual ectopic thyroid with a normally located pretracheal thyroid gland. We report such a case who presented in adolescence with obstructive symptoms.

\section{Case Report}

A seventeen-year-old female presented with history of a swelling at the base of the tongue first noticed about eight months ago. The swelling gradually increased in size causing dysphagia. There was no history of pain, ulceration, or bleeding from the swelling or any symptoms of airway obstruction. Birth history, developmental milestones, and menstrual history were normal. A detailed general and systemic examination did not reveal any abnormality. Local examination revealed a pink $2.5 \times 2.5$ centimeter swelling covered with intact mucosa and visible vessels over it at the base of the tongue (Figures 1 and 2). Thyroid gland was not palpable at its normal site. Thyroid function test suggested primary hypothyroidism with TSH $31.6 \mathrm{mIU} / \mathrm{L}(0.4-4.0)$, T4 $50.5 \mathrm{nmol} / \mathrm{L}$ (57.9-161), and T3 $1.82 \mathrm{nmol} / \mathrm{L}$ (1.252.74). Ultrasonography of the neck showed normally located thyroid gland but both lobes were hypoplastic (Figure 3 ). FNAC from the swelling was done which showed thyroid follicular cells in loosely cohesive sheets, microfollicular as well as macrofollicular arrangements (Figure 4(a), 4(b), 4(c), and 4(d), 400x, MGG). A thyroid scan with Technetium$99 \mathrm{~m}$ showed two foci of intense uptake, one at the base of the tongue and another in the submental region consistent with dual ectopic thyroid (Figures 5 and 6). No uptake of radiotracer was seen in normal thyroid bed. She has since 


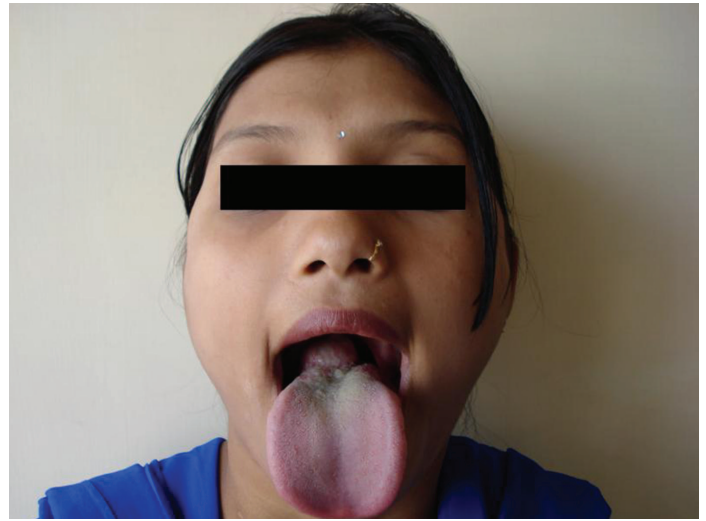

Figure 1

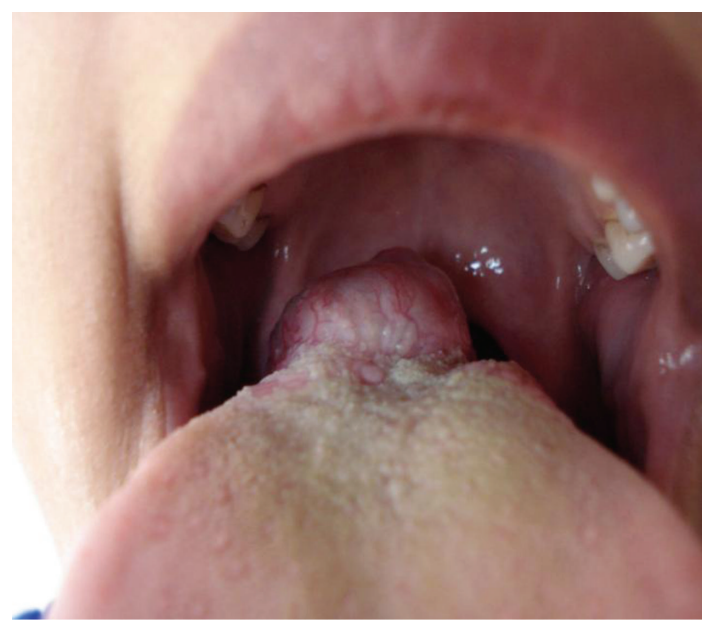

Figure 2

been put on 100 microgram of Levothyroxine daily and is on regular followup.

\section{Discussion}

Ectopic thyroid was first described by Hickman in 1869 in a newborn who was suffocated 16 hours after birth because of a lingual thyroid causing upper airway obstruction. The prevalence of ectopic thyroid tissue ranges between 7 and $10 \%$. Lingual thyroid is the most common ectopic thyroid accounting for $90 \%$ of all cases with a prevalence between $1: 100000$ and $1: 300000$ and a clinical incidence between $1: 4000$ and $1: 10000$ [1]. Other sites of ectopic thyroid are suprahyoid and infrahyoid, lateral aberrant thyroid, substernal goiters, struma ovarii, and struma cordis. Ectopic thyroid has also been found in larynx, trachea, oesophagus, pericardium, diaphragm, and branchial cysts. Rare cases of ectopic thyroid are described in parathyroid, cervical lymph nodes, submandibular gland, duodenal mesentery, adrenals, and carotid bifurcation. Ectopic thyroid occurs more commonly in females and are usually seen during adolescence and pregnancy when the demand for thyroid hormone increases [2]. Upto $70 \%$ of patients with lingual

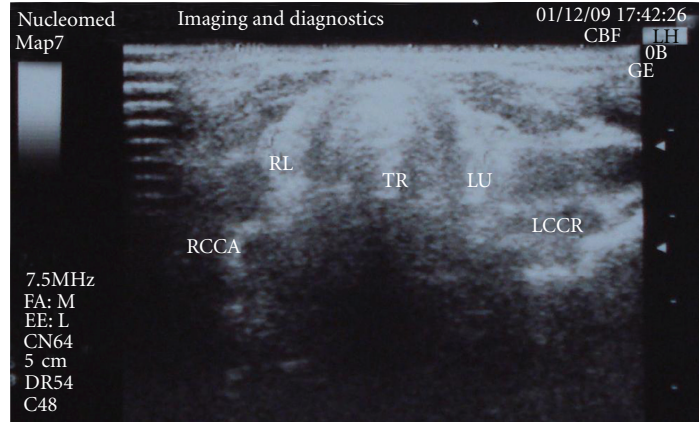

FIGURE 3

thyroid have hypothyroidism, and 10\% suffer from cretinism. Our patient also presented during adolescence with hypothyroidism. However, hyperthyroidism has been rarely described [3]. The thyroid gland is not found in its usual location in $70 \%$ of patients with ectopic thyroid [4].

Presence of two ectopic foci of thyroid tissue simultaneously is rare, and very few such cases of dual thyroid ectopia have been reported in the world literature. In an extensive review of the literature, Sood et al. found that the mean age of these patients was 15 years, more common in females with an F:M ratio of 1.25:1 [5]. The symptoms varied from asymptomatic to anterior neck swelling with or without altered thyroid status. In almost all of these patients, one site of ectopy was at lingual or sublingual region. The second ectopic focus was at subhyoid or suprahyoid level in most cases. Presence of dual ectopic thyroid with a normally located cervical thyroid is even rarer. Familial dual ectopic thyroids with perihyoid ectopic thyroid and lingual thyroid have also been described [6].

Ectopic thyroid may be asymptomatic or produce symptoms due to its location. Lingual thyroid can cause foreign body sensation in tongue, dysphagia, dysphonia, or sensation of choking. Large blood vessels present on the surface of lingual thyroid predispose it for ulceration [7]. All diseases capable of affecting the normal thyroid can affect the ectopic thyroid like adenoma, hyperplasia, inflammation, and malignancy. The rate of malignant transformation in ectopic thyroid is no greater than in normally placed thyroid. Carcinoma of the lingual thyroid is a rare clinical entity with an estimated incidence of 1\% [8]. Follicular carcinoma is the commonest histopathological subtype [8]. But at other sites papillary carcinoma is more commonly seen. Carcinoma of lingual thyroid presents in the same manner as a symptomatic patient with a lingual thyroid. Therefore, for exact pathological diagnosis a biopsy should always be taken. In our case no evidence of malignancy was found on FNAC. Ectopic thyroid can coexist simultaneously with papillary thyroid carcinoma of normal thyroid. Lingual thyroid usually has a poorly defined capsule that leads to intermingling of glandular tissue with muscle elements raising the suspicion of malignancy [9].

The most important diagnostic modality for ectopic thyroid is a thyroid scan with Technetium-99m, but ultrasonography, CT scan, and MRI may help in defining the extension 


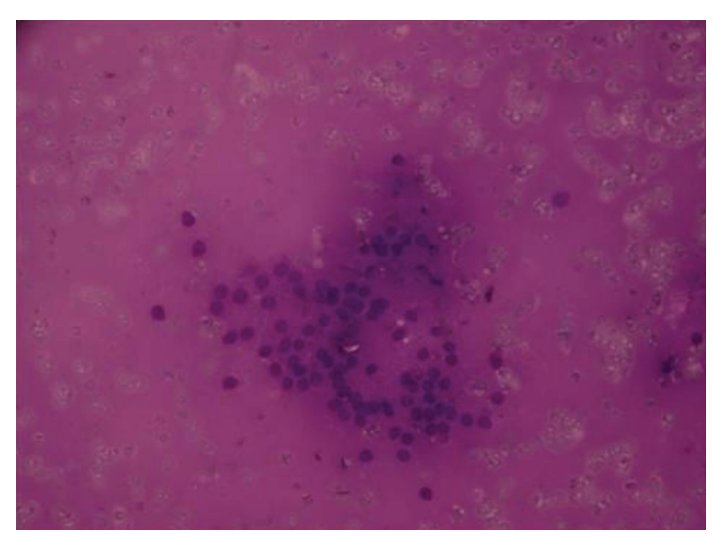

(a)

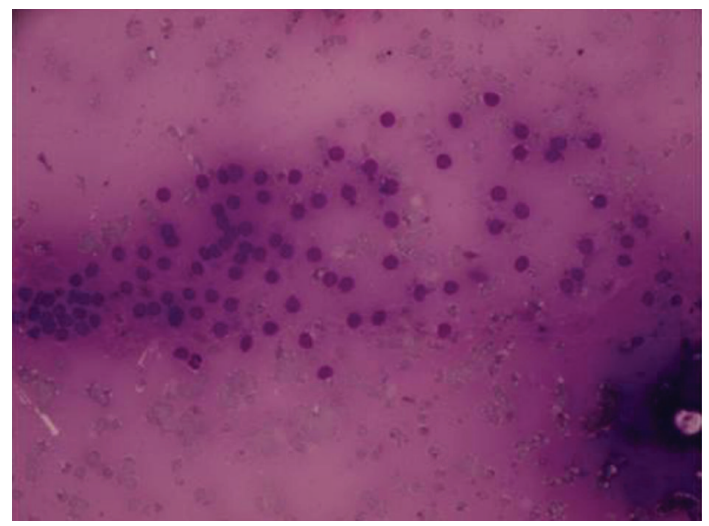

(c)

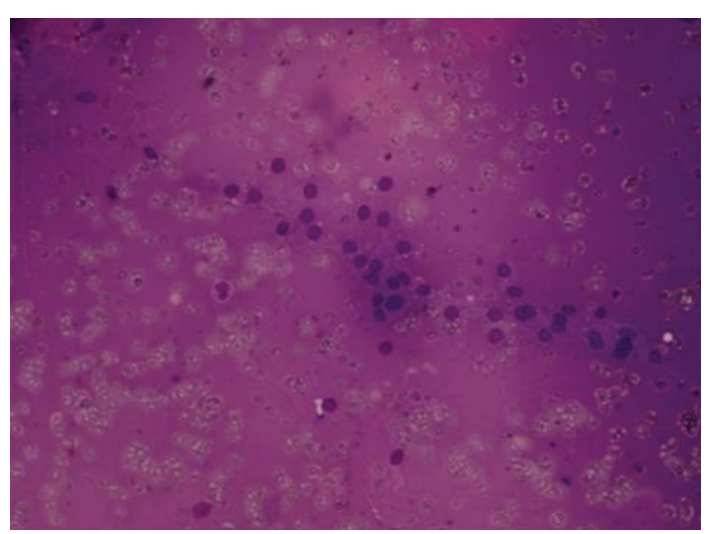

(b)

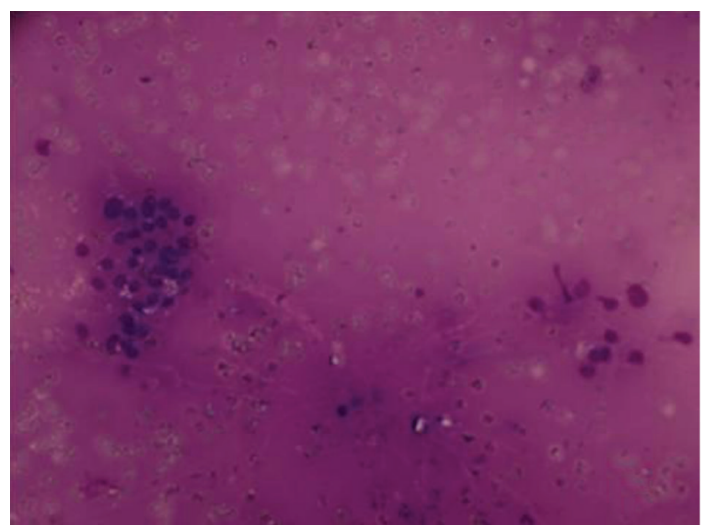

(d)

Figure 4

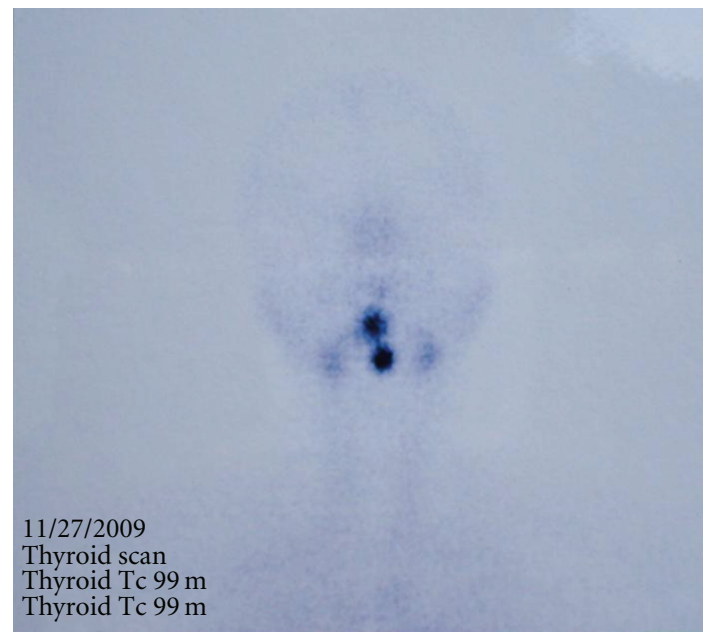

Figure 5

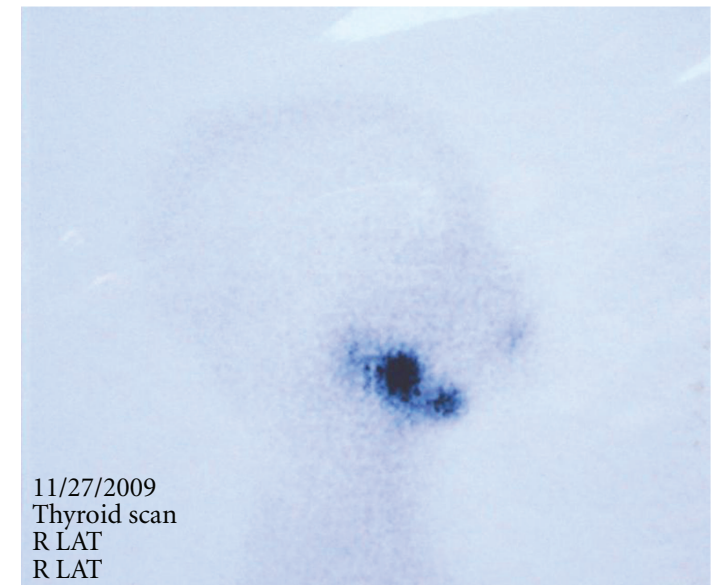

Figure 6 and location of the ectopic thyroid gland [3]. Thyroid scan also detects the presence of other sites of thyroid tissue. FNAC can also be done; however, highly vascular lingual thyroid may bleed. Asymptomatic and euthyroid patients do not require any treatment, but they should be followed up and looked after for any complications. Patients with raised TSH with swelling should be put on replacement therapy with thyroid hormone which can produce a slow reduction of the mass [3]. When medical treatment fails or there are obstructive symptoms or haemorrhage or suspicion of malignancy, then surgery should be considered. As malignant transformation has been described, some 
authors consider complete excision of ectopic thyroid as an appropriate treatment in all cases.

\section{References}

[1] A. Toso, F. Colombani, G. Averono, P. Aluffi, and F. Pia, "Lingual thyroid causing dysphagia and dysphonia," Acta Otorhinolaryngologica Italica, vol. 29, no. 4, pp. 213-217, 2009.

[2] R. Kumar, S. Sharma, A. Marwah, D. Moorthy, D. Dhanwal, and A. Malhotra, "Ectopic goiter masquerading as submandibular gland swelling: a case report and review of the literature," Clinical Nuclear Medicine, vol. 26, no. 4, pp. 306-309, 2001.

[3] M. P. Abdallah-Matta, P. H. Dubarry, J. J. Pessey, and P. Caron, "Lingual thyroid and hyperthyroidism: a new case and review of the literature," Journal of Endocrinological Investigation, vol. 25, no. 3, pp. 264-267, 2002.

[4] S. H. Baik, J. H. Choi, and L. Heung-Man, "Dual ectopic thyroid," European Archives of Oto-Rhino-Laryngology, vol. 259, no. 2, pp. 105-107, 2002.

[5] A. Sood, V. Sood, D. R. Sharma, and R. Kumar, "Thyroid scintigraphy in detecting dual ectopic thyroid: a review," European Journal of Nuclear Medicine and Molecular Imaging, vol. 35, no. 4, pp. 843-846, 2008.

[6] T. Misaki, T. Koh, S. Shimbo, K. Kasagi, and J. Konishi, "Dualsite thyroid ectopy in a mother and son," Thyroid, vol. 2, no. 4, pp. 325-327, 1992.

[7] P. Kansal, N. Sakati, A. Ritai, and N. Woodhouse, "Lingual thyroid. Diagnosis and treatment," Archives of Internal Medicine, vol. 147, no. 11, pp. 2046-2048, 1987.

[8] J. Jarvis, "Lingual thyroid: a report of three cases and discussion," South African Medical Journal, vol. 43, no. 1, pp. 8-12, 1969.

[9] J. Y. Chai and J. H. Kim, "A case of an ectopic thyroid gland at the lateral neck masquerading as a metastatic papillary thyroid carcinoma," Journal of Korean Medical Science, vol. 23, no. 3, pp. 548-550, 2008. 


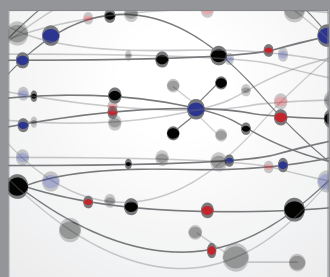

The Scientific World Journal
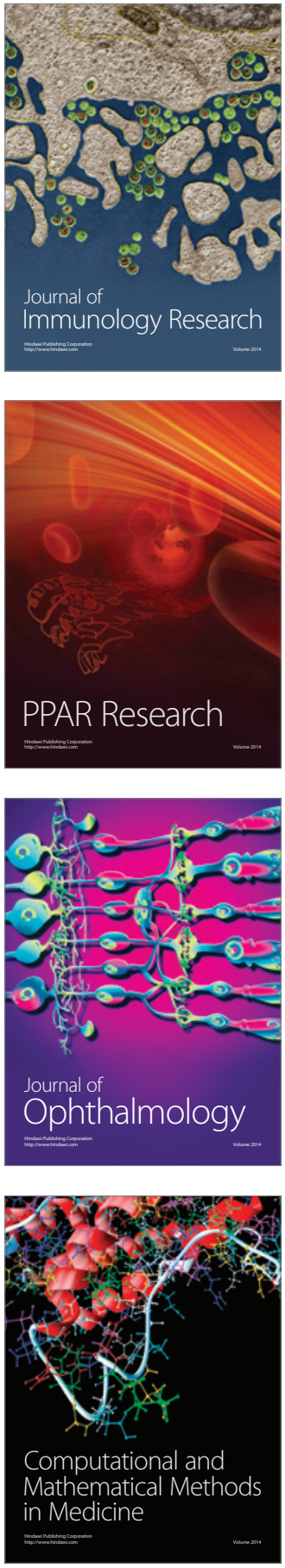

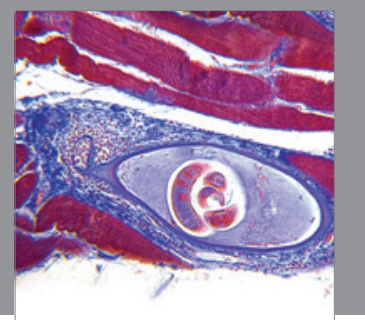

Gastroenterology

Research and Practice
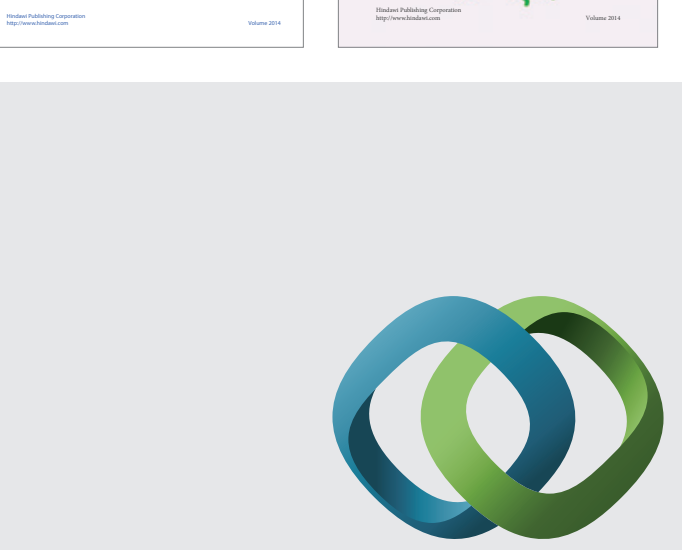

\section{Hindawi}

Submit your manuscripts at

http://www.hindawi.com
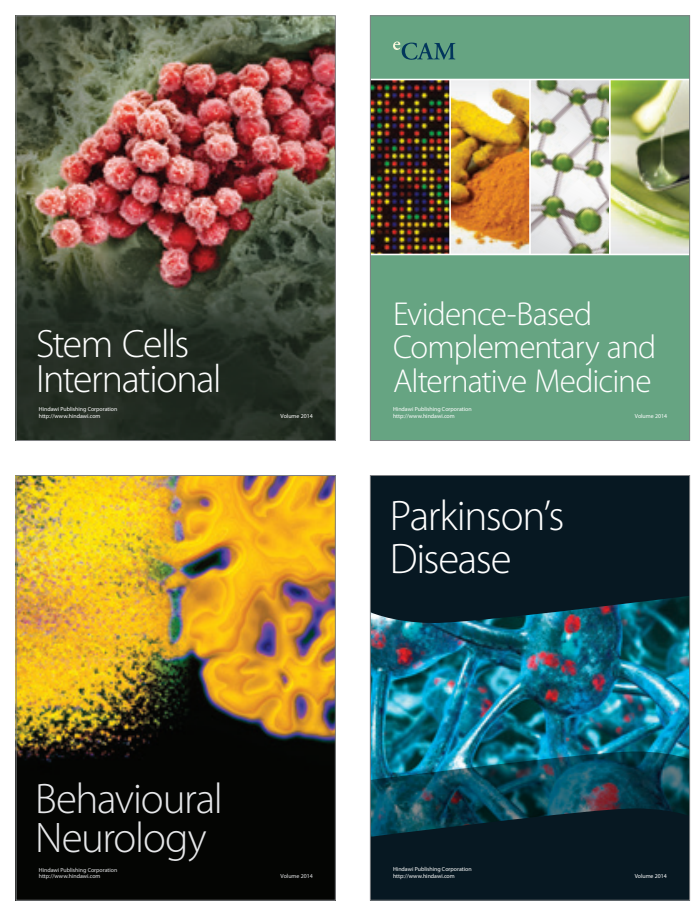

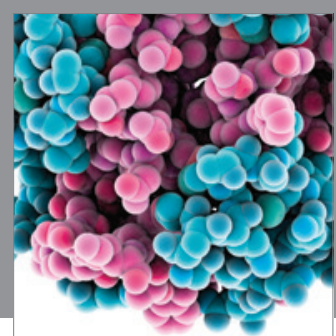

Journal of
Diabetes Research

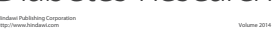

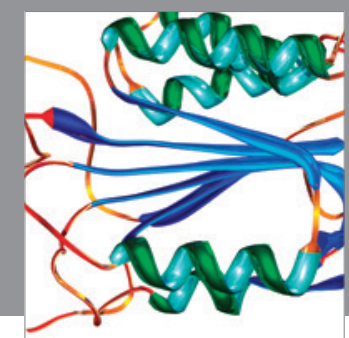

Disease Markers
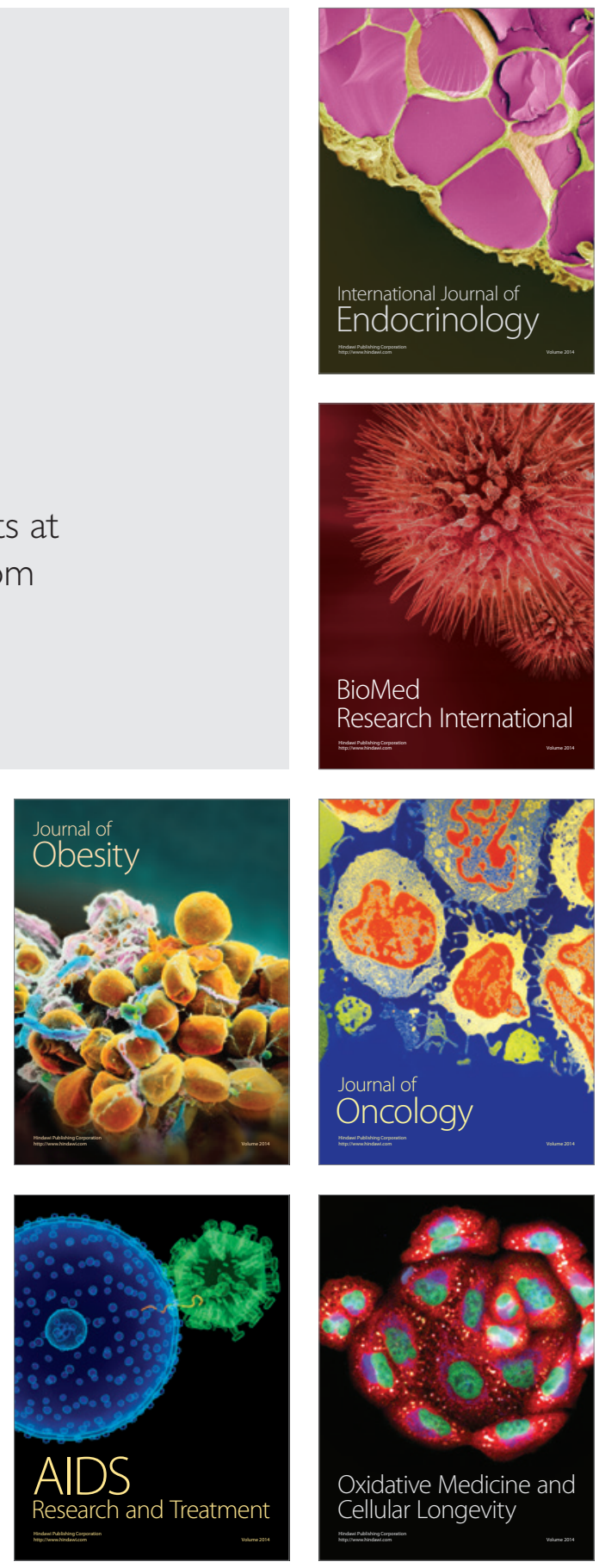